\title{
Practice, Behavior, Knowledge and Awareness of Food Safety among Secondary \& Tertiary Level Students in Trinidad, West Indies
}

\author{
Susan Turnbull-Fortune*, Neela Badrie \\ Department of Food Production, Faculty of Food and Agriculture, The University of the West Indies, \\ St Augustine, Trinidad \\ Email: ${ }^{*}$ Susan.turnbull@sta.uwi.edu
}

Received 23 May 2014; revised 29 June 2014; accepted 13 July 2014

Copyright (C) 2014 by authors and Scientific Research Publishing Inc. This work is licensed under the Creative Commons Attribution International License (CC BY). http://creativecommons.org/licenses/by/4.0/

c) (i) Open Access

\section{Abstract}

The aim of this study was to assess the level of food safety practice, knowledge, behavior and awareness among $n=205$ Trinidadian students (mean age 18 \pm ) enrolled within the education system in the Republic of Trinidad and Tobago, West Indies and to explore the association between these variables and the demographic and educational characteristics. To address these concerns, participants enrolled within the secondary (high school) and tertiary (university) institutions in Trinidad were questioned (16 questions) on food buying habits, preparation, attitudes, behaviors, knowledge and awareness. The data were analyzed using SPSS for descriptive, frequency distribution and percentages. Pearson chi square tested the association between food safety behaviors and awareness in relation to gender, age and educational level. Findings indicated that $76 \%$ of the students "always" washed their hands after touching raw chicken/meats and fish, while $50 \%$ utilized separate cutting boards/knives for raw chicken/meat and fish. Many students (68\%) believed that it was "very safe" to only rinse cutting boards used for raw chicken/meat and fish. Others $(10 \%)$ believed it was "very safe" to defrost foods outside the refrigerator, and $25 \%$ reported that it was "safe" to leave hot foods at room temperature for more than four hours. The level of food safety practice and behavior was higher $(p<0.05)$ among the female students at the secondary school level than those at the tertiary level. There was no difference in the median $(20 / 45)$ and mode $(25 / 45)$ scores for food safety behavior between the two educational groups but the difference $(p<0.01)$ was significant for awareness. Food safety practice, behavior and awareness skills of males at the secondary level were significantly lower $(p<0.01)$ than the females. These results strengthen the need for continuous educational programs to improve food safety awareness skills of Trinidadian students. 


\section{Keywords}

\section{Food Safety Behavior, Awareness, Secondary and Tertiary, Trinidad}

\section{Introduction}

Previous studies have demonstrated that food safety knowledge among secondary and tertiary students is limited and therefore, warrants attention. Knowledge of food safety should be addressed at an early stage in the educational institutions of Trinidad and Tobago. This aspect is very important among students [1], since they are also consumers. Food safety education requires basic training in safe food handling practices, preparation and storage of foods. Graduates from educational institutions are likely to become stakeholders in influential sectors of society, such as the health sector and food industry. Therefore, there is a need to investigate food safety practices, behavior, knowledge, and awareness among secondary and tertiary level students in Trinidad, West Indies because of their roles in the health of future generations [2]. Lifestyles such as a student's eating habit could have an effect on his or her present health and well-being, as habit established during early childhood can continue into later life [3]. This type of practice is indicative of statements made in another study done on the food safety attitude of culinary arts based students in public and private higher learning institutions which states that "Even if the food safety attitudes become more positive, they may not facilitate behavior change", and "When there is an attitude change, the new attitude overrides but might not replace the habitual attitude [4]".

Eating occasions outside home may also contribute to food borne illnesses, due to the mishandling of food causing cross contamination [5]. Eating patterns also have changed since many foods may be stored unrefrigerated in vehicles, sports bags, or desk drawers for a quick snack "or meal on the go" [5]. A review carried out in the Caribbean by CAREC/PAHO/WHO during the period 1981-2005 revealed that of the 42,973 cases of food borne illnesses, Trinidad and Tobago, West Indies reported an annual average of 633 cases over the period [6]. A study also investigated consumers' perceptions and awareness of in-home food safety practices in Trinidad and Barbados, West Indies over 12 months and revealed 29.7\% of family members in Trinidad, West Indies experienced food-borne illness, as compared with those in Barbados, West Indies (6.7\%) [7]. Family members experienced food-borne illness, but no one associated it with food prepared and served in the home. Therefore, the objectives of this research were to determine food safety practices, behaviors, knowledge and awareness among secondary and tertiary students within the education system of Trinidad, West Indies. There are limited research findings to determine practices, behavior, knowledge and awareness among secondary (high school) and tertiary level (university) students in Trinidad, West Indies. The implications of this study are that educators and parents may use training/education as a reliable impact tool to enhance subsequent practices, behavior, knowledge, and awareness changes among students.

\section{Sampling and Methods}

An online search was done to determine the exact number of secondary and tertiary level educational institutions in the Republic of Trinidad and Tobago, West Indies. The online search revealed that there were two hundred and twenty four secondary schools (high schools) in Trinidad and fifteen in Tobago. There are also four major tertiary level (universities) educational institutions in Trinidad \& Tobago, West Indies. This research was conducted during the months of September to December 2011 using students from the upper level (16 - 18 years old) secondary school students and tertiary level (18 years and over) students in Trinidad, West Indies. The sample size was calculated based on the precision of a study and proportionate representation [Equation (1)] [8].

$$
n=\frac{1.96^{2} \times 0.8 \times 0.2}{0.0025}=246
$$

All secondary school students, who participated in this research should have completed seven years of primary level education and would have completed the Secondary School Assessment Examination before moving onto a secondary school. After leaving secondary school, students, would have completed between 10 to 12 years of education. The secondary school students who participated in this research fell within the age group 16 18 years old and did not need parental consent. The tertiary level students were post-secondary level students 
and were first year students at the University of the West Indies (UWI), St Augustine, Trinidad, West Indies and the School of Business and Computer Science, Trincity, Trinidad, West Indies. The students were recruited using convenience sampling and a consent letter (Appendix 1) was attached to each questionnaire (Appendix 2) informing each participant of the purpose of the research with the understanding that confidentiality was assured. About half (47.3\%) of the students were from secondary schools and $52.7 \%$ of the students were from the tertiary level educational institutions.

Data was collected using a hand written questionnaire. In order to determine the allotted time of completion (approximately 10 minutes) the questionnaire was pilot-tested using fifteen students enrolled in various courses at the University of the West Indies, St Augustine, Trinidad, West Indies. The questionnaire consisted of eighteen multiple choice questions with varied possible answers, including "do not know". Questions were adapted from a Consumer Awareness and Knowledge Study [9]. All students signed a consent letter before participating in the research and were guaranteed confidentiality. The letter was attached to the questionnaire.

The questionnaire was administered face-to-face and comprised of seven areas as follows: demographics, food buying habits, preparation and attitudes, food safety behavior, food safety awareness, safety messages, and self assessment of food safety knowledge. The demographic data included gender, age, school, and household characteristics, such as composition of the household and household income, before tax. The respondents' food buying habits, food preparation, and attitudes were determined by asking questions, such as: How often do you shop for food either for yourself or others in your household? Where do you mainly shop for food, bought for either yourself or others in your household? Apart from yourself, who else do you prepare food for in your household? How often do you prepare, handle or cook poultry, meat and fish? Do you enjoy preparing food for your household?

Questions 8 and 9 were the only two questions for which students were allotted scores. These scores were used to form the basis for analyzing the practice, behaviors and awareness of the participants. Question 8 (a - i) consisted of nine Likert style multiple choice questions related to food safety behaviors. The response choices for these questions were "always," "most of the time," "sometimes," "rarely," "never," and "no response." The correct response for Question 8 (a - c) was "always," and the correct response for Question 8 (d - i) was "never." Question $9(\mathrm{a}-\mathrm{j})$ consisted of ten Likert style multiple choice questions related to food safety awareness. The response choices for these questions were "very safe," "safe", "neither safe nor unsafe," "unsafe," "very unsafe" and "no response." The correct response for Question 9 (a - c) was "very safe" and the appropriate response for Question 9 (d - j) was "very unsafe.” For Question 8 and Question 9 a score of five was allotted for all correct responses. All responses categorized as incorrect; was allotted a score of zero. Therefore Question 8's total score was out of 45 and Question 9's total score was out of 50.

The questionnaire was pilot-tested using 15 students enrolled in various courses at the UWI, St. Augustine campus from May to July of 2011. Respondents who participated in the pilot test were not included in the final data. The pilot testing was done to determine the allotted time of completion, "fine tune" the wording, check for lack of clarity of the instructions and guide the originality of this research. An introductory letter with a designated "consent" section was attached to the questionnaire. Each participant was apprised of the research and was assured of confidentiality.

\section{Statistical Analysis}

IBM SPSS Statistics 19 (SPSS Inc., Armonk, NY: IBM Corp.) was used to analyze data collected from the completed questionnaires. In all cases, the answers to the questionnaire were coded numerically and the data inputted manually into the statistical program before analysis. The data were also analyzed using cross tabulation to acquire information such as descriptive statistics, frequency distribution, and percentages. Pearson chi square was used to test the association between food safety behaviors and awareness in relation to the variables of gender, age and educational level. The Mann-Whitney $U$ test was used to determine any significance in knowledge behaviors and awareness between the male and female students at the tertiary and secondary level.

\section{Results}

\subsection{Demographics}

Of the 205 students questioned during the period September-December 2011, 97 students (47\%) were from the secondary school and $44 \%$ fell within the age range of 16 to 18 years of age and 108 (53\%) were from the ter- 
tiary level and 56\% fell within the age range of 18 years and over (Table 1). The annual household income of all respondents (was based on the conversion of \$6.4 Trinidad \& Tobago dollar $=1$ US\$) before tax. Data revealed that $8 \%$ of the respondents earned less than US $\$ 3125$, while $9 \%$ earned between US $\$ 3125$ - US $\$ 6250$, $4 \%$ earned

Table 1. Demographic characteristics $(n=205)$.

\begin{tabular}{cc}
\hline Gender, Age group, Educational Institution & Total \% \\
\hline Gender: $(\mathrm{n}=205)$ & \\
Males & 36.00 \\
Females & 64.00 \\
Age Group ( $=205)$ & \\
18 years \& Over & 56.10 \\
16 - 18 years & 43.90 \\
School: (n = 205) & \\
Secondary & 47.30 \\
Tertiary & 52.70 \\
\hline
\end{tabular}

\begin{tabular}{|c|c|c|c|}
\hline Household Composition & Responses-Secondary Students $(\mathbf{n}=97)$ & Male \% & Female \% \\
\hline \multirow{11}{*}{$\begin{array}{l}\text { Which of the following } \\
\text { best describes your household? }\end{array}$} & Living with parents & 5.15 & 42.26 \\
\hline & Living alone & 0.00 & 1.03 \\
\hline & Two or more adults and no children & 1.03 & 5.15 \\
\hline & One or more adults and children & 1.03 & 32.98 \\
\hline & No response & 3.09 & 8.24 \\
\hline & \multicolumn{3}{|c|}{ Responses-Tertiary Students $(\mathrm{n}=108)$} \\
\hline & Living with parents & 34.25 & 20.37 \\
\hline & Living alone & 8.33 & 0.92 \\
\hline & Two or more adults and no children & 4.62 & 1.85 \\
\hline & One or more adults and children & 11.11 & 17.59 \\
\hline & No response & 0.00 & 0.92 \\
\hline \multirow{8}{*}{$\begin{array}{l}\text { Annual household } \\
\text { income before tax }\end{array}$} & Responses-Secondary Students $(n=205)$ & Male \% & Female \% \\
\hline & Less than US\$ 3125 & 2.92 & 4.87 \\
\hline & US\$ 3125 to under US $\$ 6250$ & 3.41 & 5.36 \\
\hline & US $\$ 6250$ to under US $\$ 9375$ & 1.95 & 1.95 \\
\hline & US $\$ 9375$ to under US $\$ 12,500$ & 1.46 & 1.95 \\
\hline & US $\$ 12,500$ or & 2.92 & 3.90 \\
\hline & Don’t know & 20.48 & 41.95 \\
\hline & No response & 2.43 & 4.39 \\
\hline
\end{tabular}


US $\$ 6250$ to under US $\$ 9375$, 3\% earned US $\$ 9375$ to under US $\$ 12,500$ and $7 \%$ earned US $\$ 12,500$ or more. Of the 205 respondents $20 \%$ of the males and $42 \%$ of the females did not know their family's annual household income before tax and $2 \%$ of the males and $4 \%$ of the females gave no response. Respondents not knowing their family's annual income were primarily from the secondary school system. No males at the secondary school level responded to the annual income ranges of US $\$ 3125$ - US $\$ 6250$ and US $\$ 12,500$ or more. $20 \%$ female and $34 \%$ male respondents at the tertiary level and $42 \%$ female and $5 \%$ male respondents at the secondary level indicated that they still lived with their parents.

\subsection{Food Buying Habits, Preparation and Attitudes}

There was a preference for purchasing foods on a weekly basis as $42 \%$ of the females and $3 \%$ of the males at the secondary school level and $19 \%$ females and $22 \%$ males at the tertiary level preferred weekly purchases. $84 \%$ of the respondents $(n=205)$ indicated that they mainly shopped at the supermarket for food. More than half were female (55\%) students and $29 \%$ were males, followed by $4 \%$ females and $4 \%$ males indicating restaurants and $3 \%$ females and 3\% males indicating the marketplace. At the secondary level 55\% females $(\mathrm{p}<0.05)$ and $5 \%$ males, together with $21 \%$ females and $27 \%$ males at the tertiary level indicated that they prepared meals for someone other than themselves. Also, 34\% females and 5\% males at the secondary level and $19 \%$ females and $31 \%$ males at the tertiary level indicated that they did not prepare meals for anyone at home.

Many of the female (45\%) respondents and $1 \%$ of the male respondents at the secondary school level indicated that they prepared, handled or cooked chicken on a weekly basis $(p=0.01)$ while $13 \%$ of the females and $14 \%$ of the males at the tertiary level indicated that they handled chicken on a weekly basis. The female students at the secondary level showed a significantly higher $(\mathrm{p}<0.01)$ level of enjoying food preparation in response to the whether or not they enjoyed preparing food for their household. At the secondary level, 35\% females and $0 \%$ males and at the tertiary level, $9 \%$ females and $12 \%$ males indicated that they prepared, handled or cooked other meats or fish on a weekly basis. There was a significant difference between the number of males $(p<0.05)$ at the secondary level and the tertiary level who prepared, handled or cooked other meats or fish on a weekly basis. At the tertiary level $25 \%$ of the males and $12 \%$ females indicated that they never did. At the secondary level $13 \%$ of the females and 5\% males indicated that they never did this chore. Overall the female students at the secondary school showed a higher level of food buying habits, preparation and attitudes than the tertiary level females.

\subsection{Food Safety Behaviors}

On investigating the food safety behaviors (Table 2) $81 \%$ of female and $8 \%$ of male students at the secondary level and $38 \%$ of female and $45 \%$ of female students at the tertiary level indicated that they "always" wash their hands after touching raw chicken /meat. The percentage was significantly higher $(\mathrm{p}<0.05)$ among the female students at the secondary school level. There was no significant difference between the $77 \%$ female and $8 \%$ male students at the secondary school level and the $38 \%$ female and $49 \%$ male students at tertiary level who indicated that they "always" wash their hands after touching raw meat/fish. At the secondary level $35 \%$ female and $7 \%$ male students and $33 \%$ female and $24 \%$ male students at the tertiary level indicated "always" using separate cutting boards or knives for just raw chicken/meat. Of the 205 respondents, 51\% of the students indicated "always," $15 \%$ indicted" most of the time" and 16\% indicated "sometimes" for using separate cutting boards or knives for raw chicken or meat. These results indicated a high level of cross contamination prevention at both schools but the significance $(\mathrm{p}<0.05)$ was noted at the secondary school level. $77 \%$ female and $8 \%$ male students at the secondary level and 33\% female and 36\% male students at the tertiary level "always" rinsed with water only cutting boards, knives and plates used for raw chicken before using them for other foods. The students at both the secondary and tertiary level did not practiced a higher level of safe food safety behaviors ( $\mathrm{p}<$ 0.05 ) as this practice can create a significantly high risk for cross contamination. Some (30\%) of all the respondents indicated that they "never" leave cold foods out of the refrigerator for more than four hours. Eighty one percent (81\%) of female and $9 \%$ of male students $32 \%$ females $44 \%$ males at the tertiary level "never" practiced putting cooked meats back into the same plate used to store raw meats without washing them first. This practice indicated a high level of food safety behaviors however there was no significance in gender or education level. Of the $n=205$ respondents, $76 \%$ indicated that they "never" pour marinades that contained raw meat over cooked meat and 37\% indicated "sometimes" leaving hot foods at room temperature for more than 4 hours with $35 \%$ indicating that they "always" defrost frozen foods outside the refrigerator. 
Table 2. Food safety behaviors of all respondents $(\mathrm{N}=205)$.

\begin{tabular}{|c|c|c|c|c|c|c|}
\hline $\begin{array}{l}\text { Question \# } 8 \\
\text { Using the scale, can you tell me how often you do } \\
\text { any of the following things when preparing food? }\end{array}$ & $\begin{array}{c}\text { Always } \\
\%\end{array}$ & $\begin{array}{c}\text { Most of } \\
\text { the time \% }\end{array}$ & $\begin{array}{c}\text { Sometimes } \\
\%\end{array}$ & $\begin{array}{c}\text { Rarely } \\
\%\end{array}$ & $\begin{array}{c}\text { Never } \\
\%\end{array}$ & $\begin{array}{c}\text { No response } \\
\%\end{array}$ \\
\hline \multicolumn{7}{|c|}{ (a) Wash your hands after touching raw chicken/meat } \\
\hline Male & $28.3^{*}$ & 4.4 & 0.5 & 0.5 & 1.5 & 1.0 \\
\hline Female & $58.0^{*}$ & 3.9 & 0.0 & 0.0 & 2.0 & 0.0 \\
\hline \multicolumn{7}{|c|}{ (b) Wash your hands after touching raw meats or fish } \\
\hline Male & $30.2^{*}$ & 2.9 & 1.0 & 1.5 & 0.0 & 0.5 \\
\hline Female & $56.1^{*}$ & 3.9 & 2.0 & 2.0 & 0.0 & 0.0 \\
\hline \multicolumn{7}{|c|}{ (c) Use separate cuttings boards or knives for just raw chicken meat } \\
\hline Male & $21.0^{*}$ & 2.9 & 2.9 & 2.9 & 4.9 & 1.0 \\
\hline Female & $29.8^{*}$ & 11.7 & 12.7 & 4.9 & 5.4 & 0.0 \\
\hline \multicolumn{7}{|c|}{ (d) Rinse cutting boards, knives and plates used for raw chicken before using them for other food } \\
\hline Male & 22.9 & 5.4 & 3.4 & 1.5 & $1.5^{*}$ & 1.0 \\
\hline Female & 54.1 & 6.3 & 1.5 & 0.5 & $2.0^{*}$ & 0.0 \\
\hline \multicolumn{7}{|c|}{ (e) Leave cold food out of the fridge for more than 4 hours } \\
\hline Male & 1.0 & 2.4 & 10.7 & 12.2 & $9.3^{*}$ & 0.0 \\
\hline Female & 2.9 & 2.0 & 17.6 & 21.0 & $21.0^{*}$ & 0.0 \\
\hline Male & 1.0 & 1.0 & 1.5 & 3.4 & $28.3^{*}$ & 0.5 \\
\hline Female & 1.5 & 1.5 & 2.4 & 4.4 & $54.1^{*}$ & 0.0 \\
\hline \multicolumn{7}{|c|}{ (g) Pour marinades that contained raw meat over cooked meat } \\
\hline Male & 0.5 & 2.0 & 3.9 & 2.4 & $26.3^{*}$ & 1.0 \\
\hline Female & 1.5 & 1.5 & 3.4 & 6.8 & $49.8^{*}$ & 1.0 \\
\hline \multicolumn{7}{|c|}{ (h) Leave hot foods at room temperature for more than 4 hours } \\
\hline Male & 4.4 & 6.8 & 13.2 & 8.8 & $2.4^{*}$ & 0.0 \\
\hline Female & 6.3 & 10.2 & 23.4 & 14.1 & $9.8^{*}$ & 0.5 \\
\hline \multicolumn{7}{|l|}{ (i) Defrost frozen foods outside the refrigerator } \\
\hline Male & 12.2 & 9.3 & 9.8 & 1.5 & $2.0^{*}$ & 0.5 \\
\hline Female & 22.0 & 19.5 & 12.7 & 5.9 & $3.4^{*}$ & 1.0 \\
\hline
\end{tabular}

$\mathrm{N}=$ total number of respondents; ${ }^{*}$ Percentage of respondents who answered questions correctly.

Further analysis revealed that no one knew the temperature of their refrigerator at home. A significantly high $(\mathrm{p}<0.01)$ level of female students at the secondary level gave no response. $67 \%$ of the secondary level students and $70 \%$ of the tertiary level students did not know whether the temperature in their refrigerator was in Celsius or Fahrenheit. At the secondary school level the female students practiced a significantly higher $(\mathrm{p}<0.05)$ level of food safety behaviors than the males. On average the males at the tertiary level practiced higher levels of food safety behaviors than their female counterparts. Therefore at the tertiary level the male students showed a higher level of food safety practice and scored higher on both the behavior and awareness questions with no significant difference. The range of behavior scores for the secondary school students was 0 - 35 out of 45 and 0 - 30 out of 
45 for the tertiary level students, there was no significant difference in the food safety behavior mean scores (22/45) at the secondary school level and at the tertiary level (21/45). The median score for food safety behavior of both institutions was 20/45 and the mode score for both institutions was 25/45. Overall female students at the secondary school level practiced a significantly higher $(\mathrm{p}<0.05)$ level of food safety behaviors.

\subsection{Food Safety Awareness, Messages and Knowledge}

On investigating food safety awareness (Table 3 ) the majority of respondents (76\%) indicated that it was "very safe" to wash hands after touching raw chicken/meat/fish. Also 50\% of the students indicated that it was "very safe" to use separate cutting boards or knives for raw chicken/meat. These results showed a significantly high level of food safety awareness among the students with a significant difference of $p<0.01$ among the female students at the secondary school level. $68 \%$ of the $(n=205)$ students felt that it was "very safe" to rinse with water only cutting boards, knives and plates used for raw chicken. The female students at the secondary level showed a significant $(p=0.009)$ higher level in terms of lack of awareness for cross contamination and positive food safety awareness habits compared to the male students. The female students at the tertiary level showed a significant $\mathrm{p}=0.05$ lower level of awareness for cross contamination than their male counterparts. Overall the majority of students showed a lack of awareness of cross contamination.

$7 \%$ of the (n-205\%) respondents felt that it was "very unsafe" to leave cold food out of the refrigerator for more than four hours while $54 \%$ felt that it was "very unsafe" to put cooked meats back into the same plates used to store raw meats without washing them first. At the secondary level $38 \%$ females and $4 \%$ males felt that it was "very unsafe" to pour marinades from raw meat over cooked meat with $19 \%$ females and $24 \%$ males at the tertiary level expressing the same view. A significant $\mathrm{p}<0.05$ was noted for males at the secondary level as the majority of them were unaware of the risks associated with the area of cross contamination. At the secondary level, $44 \%$ of the females and $1 \%$ of males and $12 \%$ of the females and $22 \%$ of the males at the tertiary level felt that it was "safe" to defrost foods outside the refrigerator. There was a significant of $p=0.05$ among the male students at the secondary level. There was no significance among the $26 \%$ of students who felt that it was "unsafe" and the 7\% who felt that it was "very unsafe" to leave hot foods at room temperature for more than 4 hours. At the tertiary level $3 \%$ of the males and $2 \%$ of the females felt that it was "very safe" to store foods at $8^{\circ} \mathrm{C}$ and at the secondary level $3 \%$ of the females and $1 \%$ of the males felt that it was "very safe" to store foods at $8^{\circ} \mathrm{C}$. The mean awareness score was (16/50) at the secondary level and at the tertiary level it was 15/50. The range of awareness scores for secondary students was 0 - 35 out of 50 and 0 - 30 out of 50 for the tertiary level students. The male students at the tertiary level showed a higher level of practicing food safety awareness and scored

Table 3. Responses to food safety awareness $(\mathrm{N}=205)$.

\begin{tabular}{|c|c|c|c|c|}
\hline \multirow{2}{*}{$\begin{array}{l}\text { Question \# } 9 \\
\text { Using the scale, how safe is it to do the following things? } \\
\text { Very safe, safe, neither safe nor unsafe, unsafe, very unsafe, no response }\end{array}$} & \multicolumn{2}{|c|}{$\begin{array}{l}\text { Correct } \\
\text { answers }\end{array}$} & \multicolumn{2}{|c|}{$\begin{array}{l}\text { Incorrect Answers } \\
\text { or no response }\end{array}$} \\
\hline & (\%) & $\mathbf{n}^{\mathrm{a}}$ & (\%) & $\mathbf{n}^{\mathrm{a}}$ \\
\hline (a) Wash your hands after touching raw chicken/meat & 76.1 & $(156)$ & 23.9 & (49) \\
\hline (b) Wash your hands after touching raw meats/or fish & 76.1 & $(156)$ & 23.9 & (49) \\
\hline (c) Use separate cuttings boards or knives for just raw chicken/meat & 49.3 & $(101)$ & $50.7^{*}$ & (104) \\
\hline (d) Rinse cutting boards, knives and plates used for raw chicken & 0.5 & (1) & $99.5^{*}$ & (204) \\
\hline (e) Leave cold food out of the fridge for more than 4 hours & 10.7 & $(22)$ & $89.3^{*}$ & (183) \\
\hline (f) Put cooked meats back into the same plates used to store raw meats without washing them first & 54.1 & (111) & $45.9^{*}$ & (94) \\
\hline (g) Pour marinades that contained raw meat over cooked meat & 42.4 & $(87)$ & $57.6^{*}$ & (118) \\
\hline (h) Defrost frozen foods outside the fridge & 3.9 & (8) & $96.1^{*}$ & (197) \\
\hline (i) Leave hot foods at room temperature for more than 4 hours & 7.3 & (15) & $92.7^{*}$ & $(190)$ \\
\hline (j) Store cold foods at 8 degree Celsius or above (46 degrees Fahrenheit) & 2.0 & (4) & $98.0^{*}$ & (201) \\
\hline
\end{tabular}

${ }^{*}$ High percentage of respondents who either answered question incorrectly or did not respond; $\mathrm{n}^{\mathrm{a}}=$ number of respondents, $\mathrm{N}=$ total number of total respondents. 
higher on both the behavior and awareness questions but the difference was significant $(\mathrm{p}<0.01)$ only for awareness. Also, the food safety awareness median (15/50) and mode (20/50) scores were the same at the secondary and tertiary level. There was no difference in the median (15/50) and mode (20/50) scores.

At the secondary school level 50\% females and 6\% males responded "yes" to seeing hearing and reading information about food safety apart from this questionnaire. These students participated in Home Economics and Food and Nutrition classes. At the tertiary level $21 \%$ males and $17 \%$ females also indicated "yes". Of the $\mathrm{n}=$ 205 respondents $15 \%$ of the females and $11 \%$ of the males indicated "no" to seeing hearing and reading information about food safety apart from this questionnaire and 13\% females and $10 \%$ males indicated that they cannot recall seeing, reading or hearing anything about food safety. Eighteen percent (18\%) of respondents at the tertiary level stated that they got food safety information from the television and the internet. Further analysis as to where students heard or read information about food safety revealed that $36 \%$ of the females and $14 \%$ of the males got information from various other sources such as the newspapers, books, parents and food labels.

At the secondary school level $52 \%$ of the female students and $5 \%$ of the male students indicated that they had formal training in food safety or food preparation. At the tertiary level $56 \%$ of the males and $36 \%$ of females indicated that they had formal training in food safety or food preparation. Participants were not scored on the knowledge questions since these questions were structured to determine the participants' self assessment of their food safety knowledge. The self assessment of perceived food safety knowledge of $23 \%$ of females and $3 \%$ of males respondents at the secondary and $7 \%$ of female and $12 \%$ male respondents at the tertiary level revealed that that they felt that their knowledge base of food safety was "very good". A further breakdown by gender demonstrated that $43 \%$ of the females and $1 \%$ males at the secondary level together with $25 \%$ females and $27 \%$ males at the tertiary felt that their food safety knowledge was "quite good". The males at the tertiary level showed a higher $(\mathrm{p} \leq 0.05)$ perceived knowledge level than their female counterparts and the males at the secondary level. The male students at the secondary level showed a significant lower knowledge level their female counterparts with a difference of significant $\mathrm{p}<0.05$. There was no significance between the females at both institutions. Overall at the secondary level the significant $\mathrm{p}<0.05$ female population and the significant $\mathrm{p}<0.05$ male population at the tertiary level showed that the knowledge base of these students reflected knowledge of food safety issues.

\section{Discussion}

\subsection{Demographics}

Age, sex, income and educational levels influence food safety knowledge and behaviors of consumers [10]. Findings from one research showed that food safety knowledge is associated with the socio demographic and academic variable by increased food safety knowledge and age [11] while another believed that there is not always a link between behaviors and knowledge [12]. In this study these variables were used to gather data which guided and formed the basis for the analyses of this research. The students at the secondary level fell primarily within the age range of 16 - 18 and at the tertiary level 18 and over. The male students at the tertiary level showed a higher level of food safety skills than their male counterparts at the secondary level. This can be attributed to the age difference among the males but the female students at the secondary level showed a higher level of food safety skills than the females at the tertiary level. This can be attributed to the fact that the majority of female students at the secondary level indicated that they still live with their parents. The male students at the secondary level were also not knowledgeable of their family's annual income before tax (Table 1).

\subsection{Food Buying Habits, Preparation and Attitudes}

There was a preference by the majority of respondents for foods to be purchased at the supermarket, as evidenced by responses from both the secondary and tertiary level students. Also, participants preparing meals for themselves or someone other than themselves were mainly females at the secondary school level. The potential for temperature abuse exists whenever foods are purchased. This abuse occurs if the temperature of raw meat rises above $10^{\circ} \mathrm{C}$ as food borne pathogenic microorganisms flourish at these temperatures [13]. In this study males and females at both the secondary and tertiary institutions practiced leaving hot foods outside of the refrigerator for lengthy periods of time. There was also evidence of temperature abuse, as noted by foods being defrosted outside of the refrigerator and cold foods being compromised when stored at incorrect holding tempera- 
tures. An investigation on consumer awareness and perceptions of safe food safety practices at homes in Trinidad, West Indies showed that the majority of the consumers claimed that they packed frozen items 'immediately' after reaching home, thereby reducing the risk of temperature rise [14]. Also, the defrosting procedures were poor by some consumers, since more than half of consumers defrosted frozen meat improperly, i.e. by placing it in a bowl and leaving in the sink at room temperature $\left(\sim 30^{\circ} \mathrm{C} ; 86^{\circ} \mathrm{F}\right)$ to thaw. The defrosting of processed meat by placing it under cold running water was also a practice of some consumers. In conforming to correct practices, slightly less than half of consumers defrosted in a chiller/refrigerator overnight or in a microwave oven [14]. Most of the students participating in this study felt that it was neither safe nor unsafe to store foods at $8^{\circ} \mathrm{C}$ or above. They also did not conform to best practices as some of them defrosted foods outside the refrigerator and sometimes left cold food out of the refrigerator for more than four hours.

\subsection{Food Safety Behaviors}

The safety of perishable foods depended on temperature control through all stages of the cold chain. These stages include the production, transport and storage of food items both in retail display and in the domestic kitchen [15]. The packing of chilled perishable food items into the refrigerator after returning home from shopping contributes to the cold chain. It is believed that many consumers do not adhere to safety guidelines of prompt refrigeration after purchasing perishable foods, separation of raw and ready to eat foods, proper dairy storage, keeping perishable foods at or below $4^{\circ} \mathrm{C}$ and following the correct procedures when thawing frozen foods [16]. Behaviors such as these help to determine the food safety attitude of consumers and can also contribute to an understanding of their actual food safety behavior [17]. Therefore the food safety attitudes of the students in this study were determined and their behaviors were found to be satisfactory except for the areas where foods were left outside the refrigerator to defrost and hot foods were left outside for prolonged periods of time before storage (Table 2). There is the belief that attitudes can have a direct influence on behavior [17] [18]. The positive practices of students in this research towards washing of hands and using separate cutting boards and knives is reflective of their food safety knowledge and should be transferred into positive behaviors and awareness towards safe food handling and preparation. These positive practices would eliminate the possibility of cross contamination and food borne illnesses. There is also the mindset that everyone is aware of the food safety procedures for handling foods, but some of the self reported food handling behaviors by students in this study does not support this belief as evidenced by a number of them rinsing of cutting boards, knives and plates used for raw chicken, meat and fish with water only before using them for other foods.

\subsection{Food Safety Awareness, Messages and Knowledge}

In the current study, students at both the secondary and tertiary level showed positive behavior and awareness skills in some areas of food safety. For example, female students at the secondary school level showed a significantly higher level of hand washing after touching raw chicken, meats and fish, while a small percentage of males did so. At the tertiary level, mainly the male students practiced safe hand washing. Food safety knowledge, attitude and food handling practices of young adults are at an insufficient level [19]. The females in this study mainly at the secondary school level were involved in food preparation on a regular basis and the analysis of data showed that the females at the secondary level food safety practices outweighed that of their male counterparts. The analogy of the students in this study was made based on the fact that slightly more than half of the females and less than ten percent of the males at the secondary school level indicated that they had training in food safety or food preparation in their Home Economics and Food preparation classes. In previous research, females displayed higher levels of food preparation practices than their male counterparts [20]. However, in terms of food safety knowledge, both males and females were at the same level [20]. The same cannot be said about the students in this research study since the males at the tertiary level were more knowledgeable than their female counterparts and the females at the secondary level showed a higher knowledge base than their male counterparts.

Safe hand washing is considered to be hands washed with hot water, soap or detergent for lathering and rinsing, followed by the use of a clean, unused hand towel or disposable paper towel for drying [21] [22]. Someone may think that they have washed their hands "when in truth and in fact," they would have only rinsed them [22]. The analysis of responses for hand washing in this research revealed that secondary level female students demonstrated higher food safety practices, behaviors, knowledge, and awareness. In this study high percentages 
(Table 3) were noted for behaviors where the majority of respondents indicated that they always rinsed the chopping board after using it for chicken, meat and fish. Also the majority of awareness responses revealed that students felt it was very safe to rinse the chopping, boards, knives and plates after using it for chicken, meat and fish. Best practice states that chopping boards should not only be rinsed but washed with soap and water and sanitized before further use. Food items can become contaminated with pathogenic microorganisms which are transferred from contaminated hands, produce and equipment such as cutting boards and knives used during food preparation. Many opportunities for cross contamination exist in the domestic kitchen during the preparation of ready to eat food items [23]. Overall, the majority of female respondents both at the secondary and tertiary level showed an awareness of basic hygiene. However, there was a lack of awareness for food safety, as the majority of students indicated that they sometimes left foods at room temperature for more than four hours and most of the times defrosted foods outside the refrigerator. Analysis of the data revealed a gap between practices, behavior, knowledge, and awareness that may increase the risk of cross contamination. A telephone survey done in Australia showed the highest occurrence of cross contamination practices to be within the age group of 17 to 35 years [23]. Another multi-state survey done among adults showed that a large percentage of young adults were less likely to wash their hands after handling raw chicken, when compared with an even larger percentage of older adults [24]. Analysis of the data in this study does not agree with this finding, since the majority of respondents indicated that they "always" washed their hands after touching raw chicken/meat. This is a positive practice as the practice of not washing or improper washing of hands can be a contributing factor to cross contamination and food borne illness. Information coming out of a surveillance study in the USA revealed that 19\% of respondents indicated that they did not wash their hands with soap and water after handling raw meat and chicken and $20 \%$ of them stated that they did not wash their cutting boards with bleach or soap after using it for raw chicken or meat [25]. Another study showed respondents reused the same equipment for cutting raw and cooked food items using the board as is or simply wiping it with a cloth. In a 2008 Trinidad study, when asked "whether a separate cutting board was used for preparing meat and vegetables" $48.4 \%$ reported "always", 30.6\% reported "sometimes" and 18.5\% "never".

Other research revealed that students did not wash or use separate cutting boards, but used the same board for raw and ready to eat foods [26]. At the secondary school level, a large majority of females in this study always rinsed their cutting boards, knives and plates used for raw chicken before using them for other food. Also, a large percentage of all the respondents in this study always rinsed cutting boards and more than half felt that it was very safe to rinse after using them for raw meats and fish. NSFMI [27] Fact Sheet states that cross contamination can result from inappropriate cleaning of cutting boards and can be avoided by the implementation of simple procedures such as the allocation of one chopping board for each food item. For example, one for raw meat, poultry and seafood, another for breads, cakes and pastries and another for fruits and vegetables. Multi colored cutting boards also aid in the prevention of cross contamination. Cutting boards should be cleaned by washing, rinsing and sanitizing after each use and once the boards become worn out, show signs of grooves or scratches from use they should be replaced as they can then harbor harmful bacteria. WHO [28] also reported that chopping boards should be adequately cleaned after use, because fresh vegetables cut on contaminated boards will show signs of cross contamination. Other research done revealed that a quarter of the respondents reported using the same cutting board for other foods after cutting raw meat or chicken without cleaning them [29]. In this research a small percentage of females and males indicated that they "sometime" use separate chopping boards. Another poor practice by some students was the leaving of hot foods out of the refrigerator for more than four hours. All the males at the secondary school level left hot foods at room temperature for more than four hours. Also, in this research, some students indicated that they "always" defrosted frozen foods outside the refrigerator, and stored cold foods at temperatures above $8^{\circ} \mathrm{C}$. No one in this study knew the temperature of their refrigerator at home and more than half of the respondents did not know whether the temperature in their refrigerator was in Celsius or not. All refrigerators in Trinidad, West Indies are equipped with a built in thermostat and manufacturer's guide for setting the temperature. Therefore a conclusion can be made that attention was not paid to the level at which the refrigerator's temperature at home is set. In another study it was noted that being in possession of a refrigerator thermometer does not guarantee its use. Research done on consumer operation of domestic refrigerators found that the top shelf of the refrigerator was the warmest part of the interior of the refrigerator [30] and another done on the temperature performance of domestic refrigerators noted that temperatures varied within the refrigerator and ranged from $4.5^{\circ} \mathrm{C}$ to $30^{\circ} \mathrm{C}$ with the vegetable component being the warmest part of the refrigerator. 
Students were also asked whether they had seen, heard or read anything about food safety before participating in this study. Mainly females indicated that they had prior knowledge of food safety. There were various responses as to where students got the information and what they recalled. Less than half of the students indicated that they saw food safety messages on the television and on the internet. At the secondary school level, students who indicated, that they had prior knowledge of food safety were mainly females at the secondary who participated in Home Economics and Food and Nutrition classes. It is the belief that food safety messages conveyed in campaigns were not always clear to the listener. In this research the females were in the majority indicating that they saw, heard and read messages about food safety before participating in this study. The major medium for these messages were the television and internet, while others such as books, food and drink labels, newspapers, home economics, and food and nutrition classes were also reported. In 2002, the Research Triangle Institute carried out a focus group study in which participants were required to discuss promotional material for the campaign known as "Fight Back" [31]. All of the participants knew the message "Wash hands and surface often" and they all understood the importance of washing hands and surfaces in order to alleviate bacterial contamination. Another slogan "Cook to prepare temperatures" was correctly defined by some of the participants as cooking foods at internal temperatures to destroy microorganisms. Other participants felt that the slogan meant that they should follow the temperatures listed on the cooking instructions or recipe. Others confused the internal temperature of the food with the oven temperature [31]. In this study less than half of all students indicated that they can recall the messages they received while a smaller percentage of the respondents indicated that they could not recall anything.

In this study, female students from secondary schools indicated that they had formal training in either food safety or food preparation. At the tertiary level, mainly the males indicated that they had formal training. Also, in this study, the female students at both the secondary and tertiary level indicated that their knowledge of safe practices when transporting, handling, preparing and cooking foods were "very good", when compared to their male counterparts.

\section{Conclusion}

In this study, students had prior knowledge of food safety as both secondary and tertiary level students indicated that they had formal training in the subject area. Also in this study, the male tertiary level students practiced higher levels of food safety behaviors and awareness than their male counterparts at the secondary level. They also showed higher level skills than their female counterparts at the tertiary level. However, the level of food safety behavior awareness skills was higher among the females at the secondary level than their male colleagues. The secondary level females also showed higher levels skills than their female counterparts at the tertiary level. Consumers' self reported food safety practices do not appear to be good predicators of their actual behavior. Research done in 2008 on Consumers' awareness of food safety from shopping to eating showed that whenever the findings of observational food safety studies were compared to self reported behavior, evidence showed, that consumers reported that they follow safety guidelines even when they did not. A large number of other published surveys reveal that respondents were aware of the importance of hand washing, cooling food to proper temperatures, keeping raw food separate from cooked foods, keeping surfaces clean and refrigerating left over foods [32]. Sanlier believes that respondents may claim to carry out the perceived "correct" behaviors in order to convey a positive image, but may not be doing so correctly.

\section{Recommendations}

This study demonstrated that a higher percentage of the male students than female respondents at the tertiary level, and a higher percentage of female students and a lower percentage of male students at the secondary level, reported having prior knowledge of overall food safety and food preparation. There were gaps noted in this study that should be addressed at the educational level. Recommendation is made for adjustments to be made to address the gaps in food hygiene and food safety issues relevant to each stage of the student's progress along the school continuum. On reaching the secondary school, these factors should also be reinforced at the forms one, two and three levels. In order to create awareness and positive attitudes, the introduction of food safety as a subject area into the curriculum at an earlier stage will best serve to bridge the gap between the pre secondary and secondary level students so that when the students get to the tertiary or post secondary level they should be well equipped to deal with food safety issues. This approach should be achieved through education, using both the 
theoretical and practical approaches. The results of this study also demonstrated deficiencies associated with cross contamination, storage and thawing of foods at wrong temperatures among secondary and tertiary students in Trinidad, West Indies. Since students did not know the temperature of their refrigerator at home, this is a clear gap in food safety knowledge. Therefore, it is important to reinforce the fundamentals of food safety at an early stage of the schools' curriculum, this is tantamount. Continued reinforcement should be introduced at the higher educational level through rigorous on campus food safety campaigns using posters and other advertising aids such as the electronic and print media as students at this level are more inclined to access these readily available medium of communication. The use of newspapers, magazines computers, ipads and iphones are common among this student population in Trinidad and Tobago, West Indies. Note should be taken that every student entering the Secondary school system in Trinidad and Tobago is supplied with a Lap top computer by the Government of Trinidad and Tobago at no cost to the student or parent. Further research should be done in this area as no evidence was found indicating that this type of research was previously done in the Republic of Trinidad and Tobago.

\section{References}

[1] Jevsnik, M., Hlebec, V. and Raspor, P. (2008) Consumers’ Awareness of Food Safety from Shopping to Eating. Food Control, 19, 737-745. http://dx.doi.org/10.1016/j.foodcont.2007.07.017

[2] Rimal, A., Fletcher, S.M., Mc Watters, K.H., Misra, S.K. and Depdhar, S. (2001) Perception of Food Safety and Changes in Food Consumption Habits. A Consumer Analysis. International Journal of Consumer Sciences, 1, 43-52.

[3] Du’Toit, L.D. (2004) Food Safety Practices and Dietary Intake of Female Students in Self Catering Residences at the Cape Technikon. http://digitalknowledge.cput.ac.za/xmlui/handle/11189/907

[4] Patah, M.O., Rashdi, A., Zuraini, M.I. and Nor, M.K. (2009) Food Safety Attitude of Culinary Arts Based Students in Public and Private Higher Learning Institutions (IPT). International Education Studies, 2, 4.

[5] Byrd-Bredbenner, C. (2002) Food Safety: An International Public Health Issue. IEJH \& E, 5, 59-74. http://www.bvsde.paho.org/bvsacd/cd42/food2.pdf

[6] Caribbean Epidemiology Centre (CAREC/PAHOO/WHO) (2006) Pan American Health Organization. Food Borne Illnesses 1981-2005.

[7] Odwin, R. and Badrie, N. (2008) Consumers' Perceptions and Awareness of Food Safety Practices in Barbados and Trinidad, West Indies-A Pilot Study. International Journal of Consumer Sciences, 32, 394-398. http://dx.doi.org/10.1111/j.1470-6431.2008.00675.x

[8] Department of Agriculture Economics and Extension (2008) Undergraduate Research Methodology and Guidelines. Faculty of Food and Agriculture St Augustine Campus Trinidad W. I.

[9] Newton, W.C. and Associates (2006) Consumer Awareness and Knowledge Study. A Research Report Food Safety Awareness.

http://www.health.vic.gov.au/archive/archive2011/foodsafety/archive/downloads/consumer awareness knowledge sur vey_report.pdf

[10] Roseman, M. and Kurzynske, J. (2006) Food Safety Perceptions and Behaviours of Kentucky Consumers. Journal of Food Protection, 69, 1412-1421.

[11] Norazmir, M.N., Noor, H.M.A., Shafurah, S.A., Shafurah, S.B., Ajau, D. and Norazianshah, H. (2012) Knowledge and Practices on Food Safety among Secondary School Students in Johor Bahru, Johor Malaysia. Pakistan Journal of Nutrition, 11, 110-115. http://dx.doi.org/10.3923/pjn.2012.110.115

[12] Byrd-Bredbenner, C., Abbot, C.M., Wheatley, V., Schaffner, D., Bruhn, C. and Blalock, L. (2008) Risky Eating Behaviours of Young Adults-Implications for Food Safety Education. Journal of the American Dietetic Association, 108, 549-552. http://dx.doi.org/10.1016/j.jada.2007.12.013

[13] James, S. and Evans, J. (1992) The Temperature Performance of Domestic Refrigerators. International Journal of Refrigeration, 15, 313-319. http://dx.doi.org/10.1016/0140-7007(92)90047-X

[14] Boodhu, A., Badrie, N. and Sookdhan, J. (2008) Consumers' Perceptions and Awareness of Safe Food Preparation Practices at Homes in Trinidad, West Indies. International Journal of Consumer Studies, 32, 41-48.

[15] Laguerre, O., Derens, E. and Palagos, B. (2002) Study of Domestic Refrigerator Temperature and Analysis of Factors Affecting Temperature: A French Study. International Journal of Refrigeration, 25, 653-659. http://dx.doi.org/10.1016/S0140-7007(01)00047-0

[16] Li Cohen, A.E. and Bruhn, C.M. (2002) Safety of Consumer Handling of Fresh Produce from the Time of Purchase to the Plate: A Comprehensive Consumer Survey. Journal of Food Protection, 65, 1287-1296. 
[17] Redmond, E.C. and Griffith, C.J. (2003) Consumer Food Handling in the Home: A Review of Food Safety Studies. Journal of Food Protection, 66, 130-161.

[18] Kraus, S.J. (1995) Attitudes and the Prediction of Behavior: A Meta Analysis of the Empirical Literature. Personality and Social Psychology Bulletin, 21, 58-75. http://dx.doi.org/10.1177/0146167295211007

[19] Sanlier, N. and Konaklioglu, E. (2012) Food Safety Knowledge, Attitude and Food Handling Practices of Students. British Food Journal, 114, 469-480. http://dx.doi.org/10.1108/00070701211219504

[20] Sanlier, N. (2010) Food Safety Knowledge and the Safe Food Handling Behaviours of Female \& Male Consumers. Pakistan Journal of Medical Sciences, 26, 653-658.

[21] Bennion, M. and Scheule, B. (2004) Introductory Foods. 12th Edition, Pearson Education International, Upper Saddled River.

[22] Hunter, B.T. (2000) So How Important Is Hand Washing? Consumers’ Research Magazine, 83, 23-27.

[23] Jay, L.S., Comar, D. and Govenlock, L.D. (1999) A National Australian Food Safety Telephone Survey. Journal of Food Protection, 62, 921-928.

[24] Shiferaw, B., Yang, S., Cieslak, P., Vugia, D., Marcus, R., Koehler, J., Deneen, V. and Angulo, F. (2000) Prevalence of High Risk Food Consumption and Food Handling Practices among Adults: A Multi State Survey, 1996-1997. The Food Net Working Group, Journal of Food Protection, 63, 1538-1543.

[25] Turnbull-Fortune, S. and Badrie, N. (2012) Perception, Attitude and Practices of Food Safety among University Students Living in Residence Halls, Trinidad, West Indies. Online International Journal of Food Science, 1, 1-11.

[26] Yang, S., Left, M.G., McTague, D., Horvath, K.A., Jackson-Thompson, J., Murayi, T., Boeselager, G.K., Melnik, T.A., Gildemaster, M.C., Ridings, D.L., Altekruse, S. and Angulo F.J. (1998) Multistate Surveillance for Food Handling, Preparation and Consumption Behaviors Associated with Food Borne Diseases 1995 and 1996. Morbidity and Mortality Weekly Report, 47, S33-S57.

[27] NFSMI-Food Safety Fact Sheet. Preventing Contamination When Using Cutting Boards. www.nfsmi.org/documentlibraryfiles/PDF/20101210094053.pdf

[28] World Health Organisation (WHO) (2007) Food Safety and Food Borne Illness Fact Sheet No. 237. http://foodhygiene2010.files.wordpress.com/2010/06/who-food_safety_fact-sheet.pdf

[29] Klentz, K.C., Timbo, B., Fein, S. and Levy, A. (1995) Prevalence of Selected Food Consumption of Preparing Behaviours Associated with Increased Risks of Food Borne Disease. Journal of Food Protection, 58, 927-930.

[30] Flynn, O.M.J., Blair, I. and McDowell, D. (1992) The Efficiency and Consumer Operation of Domestic Refrigerators. International Journal of Refrigeration, 15, 307-312. http://dx.doi.org/10.1016/0140-7007(92)90046-W

[31] Saba, A. and Di Natale, R. (1999) A Study on the Mediating Role of Intention in the Impact of Habit and Attitude on Meat Consumption. Food Quality and Preference, 10, 69-77. http://dx.doi.org/10.1016/S0950-3293(98)00039-1

[32] Griffith, C.J. and Redmond, E. (2001) Evaluating Hygiene Behavior in the Domestic Setting and the Impact of Hygiene Education. Journal of Infection, 43, 70-74. http://dx.doi.org/10.1053/jinf.2001.0854 


\section{Appendix 1}

\section{1) Young Adult Awareness and Knowledge Study}

Adapted from Consumer Awareness and Knowledge Study—A Research Report prepared by NWC for Department of Human Services (Sourced 21/06/2011)

\section{2) Introduction}

Good morning/afternoon/evening.

My name is from The University of the West Indies, St Augustine MSc Food Quality and Safety programme. I am conducting a research on food safety practices of young adults for my research project. Your school was selected for carrying out this research.

The questionnaire will take approximately 10 minutes to complete. This research will be carried out in compliance with strict privacy and the information you provide will only be used for research purposes. All your responses will be treated with the strictest confidence.

The questionnaire deals with the transportation, handling, preparation and cooking of perishable foods. By perishable foods I mean food that can cause an upset stomach or even food poisoning if it is not properly stored or handled adequately. I am looking at items such as fresh meat, dairy products, fresh fruit and vegetables.

A trophy will be given to the school that appears to be most cooperative and enthusiastic.

\section{3) Monitoring}

My supervisor will monitor this research for quality control purposes.

If you do not wish for this to occur, please let me know.

1. Ok to monitor ( )

2. Do not monitor ( )

Thanks

\section{Appendix 2}

\section{Questionnaire}

Demographics

D1 Name of School:

Please tick accordingly

\section{D2 Gender}

( ) Male

( ) Female

D3 Which of the following age groups best describes you?
( ) 18 years \& over
( ) 16 - 18 years

D4 Where is your home situated?
() South
() Central
() East
() West
( ) North

D5 Which of the following best describes your household?

\section{( )Living with parents}

( )Living alone

( ) Two or more adults and no children

() One or more adults and children

( ) No response

D6 What is the highest level of formal education you have achieved so far?

( ) Secondary

( )Tertiary

D7 Which of the following best describes your current status? 
( )Part time student

( )Full time student

D8 Which of the following categories best describes your annual household income before tax?

( )Less than US\$3,125

( )US\$3,125 to under US\$6,250

( )US\$6,250 to under US\$9,375

( )US\$9,375 to under US\$12,500

( )US $\$ 12,500$ or more

( )Don't know

( ) No response

FOOD BUYING, HABITS, PREPARATION \& ATTITUDES

Please tick accordingly

Q1 I would like to start by asking some questions about food shopping and preparation. How often do you shop for food, for either yourself or others in your household?

() Every day

() Weekly or more often

( ) Monthly or more often

( ) Less than monthly

( ) Never

Q2 Where do you mainly shop for food, bought for either yourself or others in your household?

( ) Supermarket

( ) Specialist retailers such as butchers shop, poultry shop

() Market

() Restaurants

() Other

( ) No response

Q3 Apart from yourself, who else do you prepare food for in your household?

( ) Partner

( ) Friends

( ) Children

() No one

( ) No response

Q4 How often do you prepare, handle or cook raw chicken?

( ) Every day

() Weekly or more often

( ) Monthly or more often

( ) Less than monthly

() Never

( ) No response

Q5 And how often do you prepare, handle or cook other raw meats, or fish?

( ) Every day

( ) Weekly or more often

( ) Monthly or more often

( ) Less than monthly

( ) Never

( ) No response

Q6 Do you enjoy preparing food for your household? Would you say that you

( ) Enjoy it a lot

( ) Enjoy it

( ) Neither enjoy nor not enjoy it

( ) Do not enjoy it

( ) Do not enjoy it at all

( ) No response 
Q7 How often do you prepare food, bought for either yourself or others in your household?
( ) Every day
( ) Weekly or more often
() Monthly or more often
( ) Less than monthly
( ) Never
( ) No response
FOOD SAFETY BEHAVIOUR

Q8 Using the scale, can you tell me how often you do any of the following things when preparing food. How often do you?

(a) Wash your hands after touching raw chicken meat

( ) Always

() Most of the time

() Sometimes

() Rarely

() Never

( ) No response

(b) Wash your hands after touching raw meats or fish

( ) Always

( ) Most of the time

( ) Sometimes

( ) Rarely

() Never

( ) No response

(c) Use separate cuttings boards or knives for just raw chicken meat

( ) Always

( ) Most of the time

( ) Sometimes

( ) Rarely

( ) Never

( ) No response

(d)Rinse cutting boards, knives and plates used for raw chicken before using them for other food

( ) Always

() Most of the time

() Sometimes

( ) Rarely

() Never

( ) No response

(e) Leave cold food out of the fridge for more than 4 hours

( ) Always

( ) Most of the time

( ) Sometimes

( ) Rarely

() Never

( ) No response

(f)Put cooked meats back into the same plates used to store raw meats without washing them first

( ) Always

( ) Most of the time

( ) Sometimes

( ) Rarely

( ) Never

( ) No response

(g) Pour marinades that contained raw meat over cooked meat 


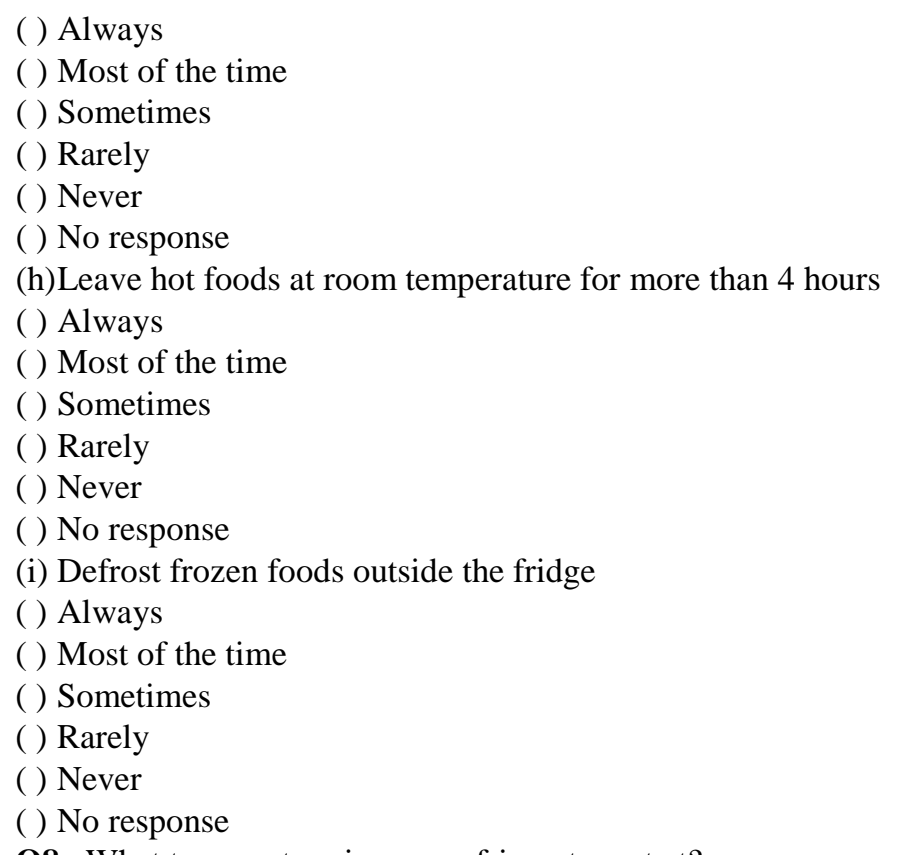

Q8a What temperature is your refrigerator set at?

(i) Record temperature

(ii) Don't know

Q8b Is this temperature in Celsius or Fahrenheit?

( ) Celsius

( )Fahrenheit

( )Don't know

\section{FOOD SAFETY AWARENESS}

Q9 In your opinion, using the scale, how safe is it to do the following things? By safe I mean that is not likely to cause food poisoning.

(a) Wash your hands after touching raw chicken meat

( ) Very safe

( ) Safe

( ) Neither safe nor unsafe

( )Unsafe

( ) Very unsafe

( ) No response

(b)Wash your hands after touching raw meats or fish

( ) Very safe

( ) Safe

( ) Neither safe nor unsafe

( )Unsafe

( ) Very unsafe

() No response

(c)Use separate cuttings boards or knives for just raw chicken meat

( ) Very safe

( ) Safe

( ) Neither safe nor unsafe

( )Unsafe

( ) Very unsafe

( ) No response

(d)Rinse cutting boards, knives and plates used for raw chicken before using them for other food

( ) Very safe 
( ) Safe

( )Neither safe nor unsafe

()Unsafe

()Very unsafe

( ) No response

(e)Leave cold food out of the fridge for more than 4 hours

( ) Very safe

()Safe

( )Neither safe nor unsafe

()Unsafe

( ) Very unsafe

( ) No response

(f)Put cooked meats back into the same plates used to store raw meats without washing them first

() Very safe

()Safe

( )Neither safe nor unsafe

()Unsafe

( ) Very unsafe

( ) No response

(g)Pour marinades that contained raw meat over cooked meat

() Very safe

()Safe

( )Neither safe nor unsafe

()Unsafe

() Very unsafe

( ) No response

(h)Leave hot foods at room temperature for more than 4 hours

( ) Very safe

( ) Safe

( )Neither safe nor unsafe

()Unsafe

( ) Very unsafe

( ) No response

(i)Defrost frozen foods outside the fridge

() Very safe

() Safe

( ) Neither safe nor unsafe

( )Unsafe

( ) Very unsafe

( ) No response

(j)Store cold foods at 8 degree Celsius or above (46 degrees Fahrenheit)

( ) Very safe

()Safe

() Neither safe nor unsafe

()Unsafe

() Very unsafe

( ) No response

\section{SAFETY MESSAGES}

Q10 Apart from this questionnaire, can you remember, seeing, hearing or reading any information about food safety?

()Yes

()No

( )Can’t recall anything 
( )No response

Q11 Where did you see, hear or read this information?

( ) No response

Q12 What did it say?

( ) No response

SELF ASSESSMENT OF FOOD SAFETY KNOWLEDGE

Q13 Would you say that your knowledge of safe practices when transporting, handling, preparing and cooking foods is?

( ) Very poor

( )Quite poor

( ) Neither poor nor good

()Quite good

() Very good

( )Don't Know

( ) No response

Q14 Which area (or areas) of food safety do you feel you understand least, and might benefit from hearing more information about?

Q15 Do you feel that you fully understand all the issues surrounding the safe buying, transporting, preparing, cooking, serving and storing of food? Is there anything else you feel that you might benefit from being given more information on?

()No

()Yes

( ) Not sure

( ) No response

Q16 Have you ever had any formal training in food safety or food preparation?

()Yes

( )No

Thank you for participating; this is the end of the questionnaire.

For quality control purposes you may be re-contacted, to verify some of the information. I will destroy your contact details when the research is completed in approximately 3 weeks time. You may contact me on matters pertaining to the questionnaire. Should you require verification of this questionnaire, bona fides, or have any queries, please feel free to contact Prof. Neela Badrie (Supervisor) @ 6622002 Ext. 83211 or Susan Turnbull-Fortune (Researcher) @ 6622002 Ext. 82396

QUESTIONNAIRE RECORD:

Participant's Name.

Participant's Phone Number.

I certify that this questionnaire was completed in a professional manner and has been checked subsequently for completeness.

Signed .Your Name (Block) 
Scientific Research Publishing (SCIRP) is one of the largest Open Access journal publishers. It is currently publishing more than 200 open access, online, peer-reviewed journals covering a wide range of academic disciplines. SCIRP serves the worldwide academic communities and contributes to the progress and application of science with its publication.

Other selected journals from SCIRP are listed as below. Submit your manuscript to us via either submit@scirp.org or Online Submission Portal.
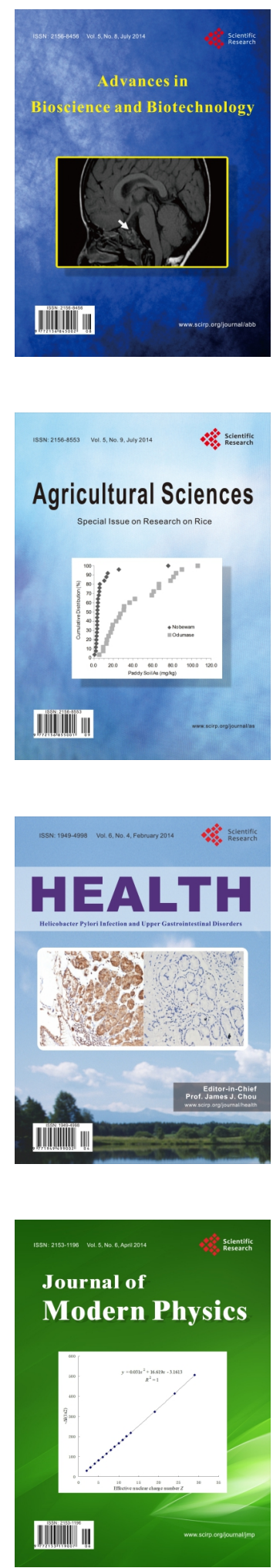
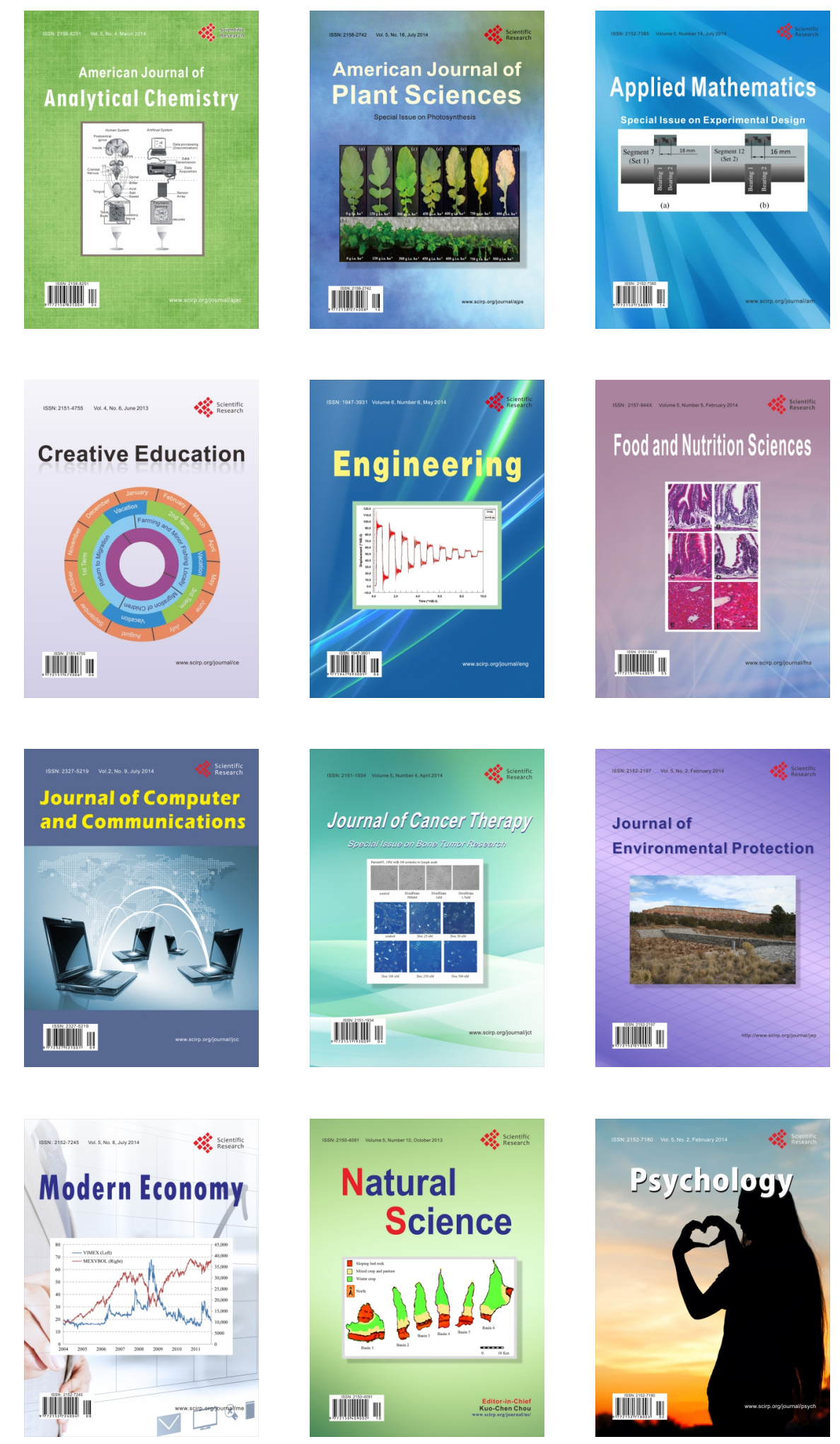